\title{
Inhibitory Effect of Thymolphthalein for Carbon Steel Corrosion in Hydrochloric Acid Solution
}

\author{
H.M. Elabbasy ${ }^{1}$, A. S. Fouda ${ }^{2, *}$ \\ ${ }^{1}$ Misr higher Institute for Engineering and Technology, Mansoura, Egypt. \\ ${ }^{2}$ Department chemistry, Faculty of Science, Mansoura University, Mansoura-35516, Egypt. \\ *E-mail: asfouda@hotmail.com,
}

doi: $10.20964 / 2019.04 .31$

Received: 12 December 2018 / Accepted: 21 January 2019 / Published: 10 March 2019

\begin{abstract}
Thymolphthalein which is mainly used as chemicalindicator, has been examined as corrosion inhibitor for carbon steel in $1 \mathrm{M}$ hydrochloric acid solution. The examinations were performed by chemical techniques (weight loss) and many electrochemical techniques (Tafel, electrochemical impedance spectroscopy, electrochemical frequency modulation), in addition to surface analysis methods (scanning electron microscopy, energy dispersion spectroscopy). The output data indicated that Thymolphthalein adsorption on the metal surface fit well to Langmuir isotherm. Inhibition efficiencies were rising with Thymolphthalein concentration and reduced as temperature increases. The performance of the investigated compound, as obtained from the used techniques, ensures the truth of these techniques in the evaluation of this inhibitor.
\end{abstract}

Keywords: Thymolphthalein, Carbon steel, Adsorption, Langmuir isotherm, Hydrochloric acid

\section{$\underline{\text { FULL TEXT }}$}

(C) 2019 The Authors. Published by ESG (www.electrochemsci.org). This article is an open access article distributed under the terms and conditions of the Creative Commons Attribution license (http://creativecommons.org/licenses/by/4.0/). 